\title{
The future of occupational therapy in mental health in Ireland
}

\author{
Chris Lloyd ${ }^{1}$ and Philip Lee Williams ${ }^{2}$
}

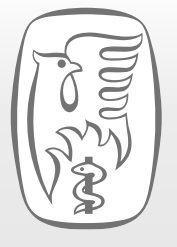

Key words:

Mental health, occupational therapy, health promotion, social inclusion, supported employment.

${ }^{1}$ Queensland Centre for Mental Health Research, Queensland, Australia. ${ }^{2}$ St Vincent's University Hospital, Dun Laoghaire, County Dublin, Ireland.

Corresponding author: Dr Chris Lloyd, Queensland Centre for Mental Health Research, Locked Bag 500, Sumner Park BC, Queensland 4074, Australia.

Email: Iloyd@onthenet.com.au

Reference: Lloyd C, Williams PL (2009) The future of occupational therapy in mental health in Ireland. British Journal of Occupational Therapy, 72(12), 539-542.

DOI: 10.4276/030802209X12601857794772

(c) The College of Occupational Therapists Ltd. Submitted: 18 November 2008.

Accepted: 14 August 2009.
The settings and roles of occupational therapists working in Ireland in mental health have changed greatly over the last decade. Occupational therapy's central tenet, however, that of focusing on occupation and the belief that it is vital in maintaining and promoting people's health and wellbeing, has not. If occupational therapists wish to remain a strong presence in mental health, they will have to adopt many generic roles and work activities while developing and maintaining unique discipline-specific roles. It is time for occupational therapists to focus on occupation, government policy and evidence-based practice in order to identify specialist roles for occupational therapy in mental health. Through this process, health promotion, social inclusion and supported employment stand out as three key areas with which occupational therapy has a good fit.

\section{Introduction}

Occupational therapy is considered to be one of the key professional groups of a modern multidisciplinary team in the area of mental health (Department of Health 2001, Mental Health Commission 2005, 2008). Despite this recognition, the role of occupational therapy is often poorly understood by members of the multidisciplinary team (Simpson et al 2005). The trend in recent history towards an increase in the number of generic roles taken on by occupational therapists and the lack of knowledge of the role of occupational therapy by other team members in mental health services are concerns for the profession. In particular, there is the fear that occupational therapy will cease to be seen as a specialist treatment provider, becoming overburdened by generic roles. This is not a new concern and has been raised previously (for example, Harries and Gilhooly 2003).

Although this is a genuine concern in a continuously changing health care environment, there are opportunities available to the occupational therapy profession to develop and champion specific roles within mental health services. The authors sought to identify emerging roles within current government policy documents (restricted to Ireland and the United Kingdom [UK] for this paper) that demonstrated a good fit with the disciplinespecific skills of the occupational therapy profession (occupation as defined by the College of Occupational Therapists 2006a, 2006b) and current evidence-based interventions. This opinion piece is primarily meant to provide information about the development of mental health occupational therapy in Ireland.

\section{Background}

Despite the fact that occupational therapy has its roots working in mental health, there are currently a limited number of occupational therapists employed in the field. Within Ireland, there are 1,025 occupational therapists employed in the public health service with only 175 occupational therapists employed in mental health (Health Service Executive 2008, 
Mental Health Commission 2008), which represents an increase of $131.5 \%$ over the period end of 2000 to end of 2007. This is a positive move and indicates the commitment of the Health Service Executive to enhanced occupational therapy services.

Community mental health centres may accommodate a day hospital, an assertive community team, a crisis team and a day service or outpatient clinic. In the field of child and adolescent mental health, there is a plan to create more beds, the psychiatry of later life is developing and there is an identified need to increase rehabilitation teams. There have been plans for the closure of all large psychiatric hospitals and to use this funding to develop community teams further. Most community services consist of a rehabilitation team, a liaison team and a psychiatry of later life team; in some areas, other specialist teams have been developed, including a homeless team and eating disorders, forensic and addiction teams. It is anticipated that a close relationship will be developed with local support, vocational and housing agencies.

It has been noted that there is a lack of research into mental health services and there is encouragement for further development in this area. The Mental Health Commission (2008) suggested that staffing resources in the community mental health teams should be increased to ensure that each team has a core multidisciplinary team. A national recruitment campaign to recruit occupational therapists commenced at the end of March 2008. This opens up many opportunities for occupational therapists to be involved in the new services and programmes that are currently being planned and developed.

In recent times, there has been a focus on redesigning mental health services away from traditional stand-alone psychiatric hospitals to more diverse service models (Mental Health Commission 2008, Richards 2008). Mental health services are focusing on the needs of the people who use them: on recovery, on health promotion and on employment and vocational opportunities (Mental Health Commission 2005, College of Occupational Therapists 2006b). This has resulted in occupational therapists working outside the recognised boundaries of occupational therapy practice, using skills and techniques not included in the defined core skills of an occupational therapist (Richards 2008).

In the last decade, there has been debate in the occupational therapy literature concerning generic and specialist occupational therapy casework in community mental health teams (for example, Parker 2001, Cook 2003, Harries and Gilhooly 2003, Harrison 2003). It appears that occupational therapists are concerned about the amount of generic working they are required to do, often at the expense of carrying out discipline-specific work activities.

In reviewing government policy documents, it is clear that multidisciplinary team based care is the future direction of government policy at present (Department of Health 2001, Mental Health Commission 2005, 2008). Identifying clear discipline-specific roles within this setting is important. The College of Occupational Therapists (2006a) recommended that if occupational therapists are to defend their professional role, it is necessary to be clear about the roles undertaken. It also recommended that occupational therapists need to provide evidence for the effectiveness of occupational therapy interventions and demonstrate that profession-specific services benefit the service user.

It has been suggested by the Department of Health (2001, p24) that the mental health system must support people in settings of their own choosing, enable access to community resources including housing, education, work, friendships - or whatever they think is critical to their own recovery'. It would seem that occupational therapy has a key role in enabling access to occupations (as defined by the College of Occupational Therapists 2006a, 2006b) for people living with a mental illness.

\section{Key development areas}

Occupational therapy in Ireland has a unique opportunity to establish a clear role and direction for the development of the profession. The roles discussed below have been identified from policy documents and are considered to have a good fit with the skills and knowledge base of the occupational therapy profession. These broad areas will provide a guiding vision and avenue for occupational therapists to focus on occupation and to outline and communicate clearly a specialist role in mental health care.

\section{Health promotion}

Health promotion has been recognised as an integral component in achieving recovery-orientated mental health systems. Health promotion is listed as one of the key development areas across Ireland and the UK (Department of Health 2001, Mental Health Commission 2005). Health promotion is a very broad term, which encompasses interventions aimed at the whole population (universal), selected high risk groups (selective) and targeted treatment groups (indicated) (Commonwealth Department of Health and Aged Care 2000). At each level, health promotion is considered as the process of enabling people to increase control over and to improve their health (World Health Organisation 1998). In essence, it is about making the healthy choice the easy choice. This process includes working with the individual and, crucially, with the social, cultural and physical environmental factors that have an impact on the adoption of healthy behaviours.

The Mental Health Commission (2005) identified three broad areas relating to mental health promotion: strengthening individuals through increasing self-esteem, coping skills and communication; strengthening communities, such as by increasing social inclusion and participation; and reducing structural barriers to mental health, such as by improving access to education and meaningful employment.

Occupational therapists are currently involved in some health promotion activities, such as health education (Mountain et al 2008) and diet and physical exercise 
(Lloyd and Sullivan 2003). Health promotion is emerging as a core skill of occupational therapy (Jones-Phipps and Craik 2008), although in practice there is limited available evidence as to the occupational therapist's role in health promotion activities (Flannery and Barry 2003). It has been found that there are a number of barriers to occupational therapy involvement in health promotion. Some of these barriers were identified as staffing levels, a lack of resources and a lack of knowledge and training availability (Flannery and Barry 2003). Further research and debate within the occupational therapy profession is required to clarify the role that occupational therapy can take at the individual, service and social policy levels.

\section{Social inclusion}

The term 'social inclusion' is often used in differing contexts. This opinion piece considers social inclusion as the ability to actively engage in activities in the community in which a person lives if he or she desires to do so (Burchardt et al 1999). Social exclusion is well documented as having active involvement in poorer health status, lower levels of quality of life and greater social disadvantage (Office of the Deputy Prime Minister 2004). The Mental Health Commission's (2005) document, A Vision for a Recovery Model in Irish Mental Health Services, outlined the requirement to implement, as standard, practice interventions and policies that support social inclusion. Addressing stigma, increasing education opportunities, improving access to housing and employment and developing community and personal development programmes are reported as key strategies to achieve this.

Occupational therapy as a profession is well placed to take a leading role in decreasing social exclusion for people living with a mental illness. The detailed understanding of how people engage in occupations and the effect that this has on their health is central to social inclusion. It is through involvement in daily occupations that people participate in the communities in which they live. It is also through this participation that they continue to learn and develop the new skills and habits that allow them to take on socially valued roles in the community (Lloyd et al 2006). This leads to a greater sense of social participation and more opportunities to develop new skills and habits.

A key component of social inclusion is the ability for people to engage in productive occupations, such as work within their communities. Lloyd et al (2006) argued that it is important for mental health practitioners to consider setting specific targets for such areas as employment, housing, education and engagement in social activities. They suggested that the promotion of social inclusion should be incorporated into every service user's care plan. Additionally, they outlined four key strategies to improve the social inclusiveness of people with mental illness. These were addressing attitudes and beliefs, promoting employment opportunities, supporting families and community participation, and addressing housing, finances, and transport and access issues.

\section{Supported employment}

Occupational therapists have a long history of being involved in vocational assessment (for example, Lloyd 1986) and work programmes for people with mental illness (for example, Du Toit 1972). Employment, whether paid or voluntary, is one of the major occupations of an individual in the modern world. Perkins and Rinaldi (2002) examined the employment status of people with severe mental illness in an inner-city borough. They found that, within the borough, the unemployment rates of people with severe mental illness increased steadily during the 1990s. This occurred despite a decreasing rate of general unemployment for the majority of that period. Unemployment among people with mental illness increased from $80 \%$ in 1990 to $92 \%$ in 1999 .

The UK government body, the Social Exclusion Unit, concluded that supported employment and the individual placement and support (IPS) model were significantly more effective than other approaches in enabling people with severe mental illness to find and maintain open employment (Office of the Deputy Prime Minister 2004). A full description of the IPS model has been presented by Bond (2004).

A recent review by Bond et al (2008) reported the results of a comprehensive literature search for randomised controlled trials of IPS and located 11 studies. These were examined for competitive employment outcomes, which were employment rates, days to first job, annualised weeks worked and job tenure in longest job held. It was found that the competitive employment rate was $61 \%$ for IPS compared with $23 \%$ for controls. About two-thirds of those who obtained competitive employment worked 20 hours or more per week. Bond et al (2008) concluded that the number, consistency and effect sizes of studies of evidence-based supported employment establish it as one of the most robust interventions available for people with severe mental illness. This presents a clear opportunity for occupational therapy as a profession to establish a specialist role in vocational rehabilitation. One way to accomplish this is to take on the role of clinical employment lead, as suggested by the Department of Health (2006). This person links closely with the employment specialist and all providers in the team. The outcome that is expected is that there will be a reduction of people on community team caseloads not involved in meaningful occupations.

It is only in recent times that occupational therapists have contributed towards publishing their work in the area of evidence-based employment (for example, Davis and Rinaldi 2004, Porteous and Waghorn 2009, Tsang et al 2009). It was suggested that occupational therapists can facilitate system change towards the routine delivery of employment services integrated with public mental health treatment and care (Porteous and Waghorn 2009). Tsang et al (2009) discussed that in order to improve vocational outcomes from IPS, it is beneficial to augment IPS with additional psychosocial interventions; for example, social skills training. This provides occupational therapists with the opportunity to participate in the development of programmes to augment evidence-based supported employment. 


\section{Conclusion}

In Ireland, it is a time of change and there are many opportunities for occupational therapists to develop their role further. Occupational therapy as a profession is able to take on new roles emerging within government policies. These have been discussed as health promotion, social inclusion and supported employment. These roles have been chosen owing to the strong links between them and occupation, which forms the basis of the occupational therapy profession. It is by being familiar with current knowledge and government policies that occupational therapists can outline the potential scope for occupational therapy practice in the mental health field. This is an exciting time with many challenges ahead, but it is important for the growth and development of occupational therapy in mental health that occupational therapists take a lead in defining their role and seizing these opportunities.

\section{References}

Bond GR (2004) Supported employment: evidence for an evidence-based practice. Psychiatric Rehabilitation Journal, 27(4), 345-59.

Bond GR, Drake RE, Becker DR (2008) An update on randomized controlled trials of evidence-based supported employment. Psychiatric Rehabilitation Journal, 31(4), 280-90.

Burchardt T, Le Grand J, Piachaud D (1999) Social exclusion in Britain 1991-1995. Social Policy and Administration, 33(3), 227-44.

College of Occupational Therapists (2006a) Recovering ordinary lives. The strategy for occupational therapy in mental health services 2007-2017. A vision for the next ten years. London: COT.

College of Occupational Therapists (2006b) Recovering ordinary lives. The strategy for occupational therapy in mental health services 2007-2017. Literature review. London: COT.

Commonwealth Department of Health and Aged Care (2000) Promotion, prevention and early intervention for mental health - a monograph. Canberra: Mental Health and Special Programs Branch, Commonwealth Department of Health and Aged Care.

Cook S (2003) Generic and specialist interventions for people with severe mental health problems: can interventions be categorised? British Journal of Occupational Therapy, 66(1), 17-24.

Davis M, Rinaldi M (2004) Using an evidence-based approach to enable people with mental health problems to gain and retain employment, education and voluntary work. British Journal of Occupational Therapy, 67(7), 319-22.

Department of Health (2001) The journey to recovery - the Government's vision for mental health care. London: Department of Health Publications.

Department of Health (2006) Vocational services for people with severe mental health problems: commissioning guidance. London: DH.

Du Toit V (1972) The restoration of activity participation leading to work participation. South African Journal of Occupational Therapy, 2, 6-10.

Flannery G, Barry M (2003) An exploration of occupational therapists' perceptions of health promotion. Irish Journal of Occupational Therapy, Winter, 33-41.
Harries PA, Gilhooly K (2003) Generic and specialist occupational therapy casework in community mental health teams. British Journal of Occupational Therapy, 66(3), 101-09.

Harrison D (2003) The case for generic working in mental health occupational therapy. British Journal of Occupational Therapy, 66(3), 110-12.

Health Service Executive (2008) Health service employment. Available at: http://www.hse.ie/eng/HSE_Facts/HSE_Staff_figures_and_information.htm/ Accessed on 06.04.09.

Jones-Phipps M, Craik C (2008) Occupational therapy students' views on health promotion. British Journal of Occupational Therapy, 71(12), 540-44.

Lloyd C (1986) Vocational evaluation in a forensic psychiatric setting. Canadian Journal of Occupational Therapy, 53(1), 31-35.

Lloyd C, Sullivan D (2003) NEW Solutions: an Australian health promotion programme for people with mental illness. International Journal of Therapy and Rehabilitation, 10(5), 204-09.

Lloyd C, Tse S, Deane FP (2006) Community participation and social inclusion: how practitioners can make a difference. Australian e-Journal for the Advancement of Mental Health, 5(3).

Mental Health Commission (2005) A vision for a recovery model in Irish mental health services. Dublin: MHC.

Mental Health Commission (2008) Mental Health Commission Annual Report 2008. Dublin: MHC.

Mountain G, Mozley C, Craig C, Ball L (2008) Occupational therapy led health promotion for older people: feasibility of the Lifestyle Matters programme. British Journal of Occupational Therapy, 71(10), 406-13.

Office of the Deputy Prime Minister (2004) Mental health and social exclusion. London: ODPM Publications.

Parker H (2001) The role of occupational therapists in community mental health teams: generic or specialist? British Journal of Occupational Therapy, 64(12), 609-11.

Perkins R, Rinaldi M (2002) Unemployment rates among patients with long-term mental health problems. Psychiatric Bulletin, 26(8), 295-98.

Porteous N, Waghorn G (2009) Developing evidence-based supported employment services for young adults receiving public mental health services. New Zealand Journal of Occupational Therapy, 56(1), 34-39.

Richards $G$ (2008) The changing face of occupational therapy in mental health. In: EA McKay, C Craik, KH Lim, G Richards, eds. Advancing occupational therapy in mental health practice. Oxford: Blackwell Publishing, 17-29.

Simpson A, Bowers L, Alexander J, Ridley C, Warren J (2005) Occupational therapy and multidisciplinary working on acute psychiatric wards: the Tompkins Acute Ward Study. British Journal of Occupational Therapy, 68(12), 545-52.

Tsang HWH, Chan A, Wong A, Liberman RP (2009) Vocational outcomes of an integrated supported employment program for individuals with persistent and severe mental illness. Journal of Behavior Therapy and Experimental Psychiatry, doi:10.1016/j.jbtep.2008.12.007

World Health Organisation (1998) Health promotion glossary. Geneva: WHO. Available at: $h$ ttp://www.who.int/healthpromotion/about/HPG/en/index.html Accessed on 01.04.07. 